American Journal of Applied Sciences 5 (7): 872-875, 2008

ISSN 1546-9239

(C) 2008 Science Publications

\title{
Quality of Life in Hematologic Cancer Patients: A Randomized Clinical Trial of Low Dose Naltrexone Versus Placebo
}

\author{
${ }^{1}$ Mohammad Ali Seifrabiei, ${ }^{2}$ Mohammad Abbasi, ${ }^{3}$ Ali Montazeri, \\ ${ }^{2}$ Fatemeh Shahnazari and ${ }^{1}$ Arash Pooya \\ ${ }^{1}$ Department of Social Medicine, Faculty of Medicine, \\ Hamedan University of Medical Sciences, Hamedan, Iran \\ ${ }^{2}$ Department of Oncology and Hematology, Faculty of Medicine, \\ Hamedan University of Medical Sciences, Hamedan, Iran \\ ${ }^{3}$ Iranian Institute for Health Sciences Research, Tehran, Iran
}

\begin{abstract}
This study aimed to investigate its effect on hematologic cancer patients. This was a randomized controlled trial assessing quality of life in patients with hematologic malignancies from a single institute in Hamedan. Patients were allocated into two study arms and in addition to their routine treatment received either daily naltrexone $3 \mathrm{mg}$ capsules (treatment group) or 3 $\mathrm{mg}$ starch (placebo group) and were followed up for 5 months. Quality of life was measured using the EORTC QLQ-C30 in four points in time (at admission, 1, 3 and 5 months follow-up). Data were analyzed to compare quality of life in two groups. Totally, 89 patients were studied (45 in treatment group and 44 in placebo group). There were no significant differences between two groups either in demographic and clinical characteristics or in baseline quality of life scores. However, at 1 month, 3 and 5-month follow-up assessments significant differences were observed. In one month follow-up two groups were significantly different in social functioning $(\mathrm{p}<0.05)$ indicating a better condition in the treatment group. In the 3-month follow-up, social functioning, role functioning, nausea and vomiting and appetite loss were better in the treatment group (all p-values $<0.05$ ). In the 5 -month follow-up, physical functioning, social functioning, role functioning, global quality of life, nausea and vomiting and appetite loss were significantly better in the nalterxone group. Low dose naltrexone is an effective drug in improving quality of life in patients with hematologic cancers.
\end{abstract}

Key words: Low dose naltrexone, quality of life, hematologic cancer

\section{INTRODUCTION}

Naltrexone is a main drug for treatment of addiction and acts by blocking opioid receptors in brain. The drug can inhibit secretion of opioids in both brain and adrenal glands (beta endorphins and enkefalins). Many tissues including almost all the immune cells have receptors for endorphins and enkefalins. In mid 1990 investigators showed that the Low Dose Naltrexone (LDN) has a dramatic therapeutic effect on different cancers such as lymphoma and pancreatic cancer as well as autoimmune disorders ${ }^{[1]}$. Until now the incredible effects of naltrexone in many chronic conditions and immune disorders is confirmed ${ }^{[2-5]}$. It is believed that endorphins (internal opioids) have a central role in immune system and preclinical investigations showed positive effect of opioids in growth development and immune cell function. Meanwhile it is under discussion that brief and short time blocking of opioid receptors by low dose naltrexone cause positive regulation of immune system via compensatory increase in enkefalins and endorphins. This was demonstrated in volunteers who had been prescribed low dose naltrexone and showed that they have had upper levels of endorphins compared with other people ${ }^{[6,7]}$. The low dose naltrexone has even been effective in neuro-

Corresponding Author: Mohammad Ali Seifrabiei, Department of Social Medicine, Faculty of Medicine, Hamedan University of Medical Sciences, Hamedan, Iran Tel: +989183136330 
Am. J. Applied Sci., 5 (7): 872-875, 2008

psychiatric disorders like childhood autism and anxiety disorders ${ }^{[8,9]}$.

Naltrexone was also shown to be effective in animals resulting in reduced withdrawal signs in laboratory mice $\mathrm{e}^{[10]}$ and regulation of cerebellar cell proliferation in other animals ${ }^{[11]}$. In vitro examinations of human cancers showed the inhibitory effect of cellular growth due to apoptosis with low dose naltrexone ${ }^{[12]}$. A common mechanism in all mentioned disorders is diminished immune responses and endorphin levels while LDN results in improved immune system and increased endorphins levels. While only few side effects reported in studies of low dose naltrexone, investigators believe that assessment of different therapeutic effects of the drug needs more clinical trials. This study was an attempt to assess quality of life in hematologic cancer patients who received LDN.

\section{MATERIALS AND METHODS}

This was a randomized clinical trial of low dose naltrexone versus placebo in patients with hematologic cancer in teaching hospitals in Hamedan (a historical province in west), Iran. Eighty-nine patients entered the study after being informed about the study and filling in an informed consent form. Since the intention was to follow up patients for at least 5 months thus patients were included in the study if a life expectancy over one year was expected. Patients were randomly assigned into two groups: 45 in naltrexone group and 44 in placebo group. The naltrexon group received $3 \mathrm{mg}$ naltrexone and the placebo group received $3 \mathrm{mg}$ starch capsules. Drugs were being delivered to patients in similar shape and size in a closed package with a code for identifying two groups. Quality of life was assessed using the Iranian version of the EORTC QLQ-C30 questionnaire in four points in time: in admission and at 1,3 and 5 months after starting the intervention. The questionnaire contains 30 items and includes 5 functioning scales, a global quality of life scale and a number of symptoms scales. Each scale is scored from 0 to 100. Higher scores for functioning and global quality of life indicate a better condition and for symptoms reflect a higher degree of symptoms.

\section{RESULTS AND DISCUSSION}

Totally, 89 patients were studied. There were no significant differences between the two groups
Table 1: The characteristics of patients

\begin{tabular}{llll}
\hline Charateristics & $\begin{array}{l}\text { Naltrexone } \\
(\mathrm{n}=45)\end{array}$ & $\begin{array}{l}\text { Placebo } \\
(\mathrm{n}=44)\end{array}$ & \\
\hline No. (\%) & No. (\%) & p-value \\
$\begin{array}{l}\text { Mean (SD) } \\
\text { Sex }\end{array}$ & $39.4(18.2)$ & $36.6(16.1)$ & 0.409 \\
Male & 23 & 22 & 0.917 \\
$\begin{array}{l}\text { Female } \\
\text { Marital status }\end{array}$ & 22 & 22 & \\
$\begin{array}{l}\text { Single } \\
\text { Married }\end{array}$ & 12 & 14 & 0.86 \\
$\begin{array}{l}\text { Widowed/divorced } \\
\text { Diagnosis }\end{array}$ & 30 & 27 & \\
$\begin{array}{l}\text { Non metastatic cancer } \\
\text { Metastatic cancer }\end{array}$ & $23(51 \%)$ & 3 & \\
\hline & $22(49 \%)$ & $17(39 \%)$ & \\
\hline
\end{tabular}

Table 2: Baseline quality of life (admission time) in the naltrexone and placebo groups

\begin{tabular}{llcc}
\hline Functioning & $\begin{array}{l}\text { Naltrexone } \\
(\mathrm{n}=45) \\
\text { Mean }(\mathrm{SD})\end{array}$ & $\begin{array}{l}\text { Placebo } \\
(\mathrm{n}=44)\end{array}$ & \\
Mean $(\mathrm{SD})$ & p-value \\
\hline Physical functioning & $70.8(3.5)$ & $69.9(4.1)$ & 0.6 \\
Role functioning & $66.1(5.9)$ & $63.5(5.2)$ & 0.3 \\
Emotional functioning & $71.8(4.3)$ & 60.1 & 0.8 \\
Cognitive functioning & $83.8(4.2)$ & 80.6 & 0.9 \\
Social functioning & $70.8(4.4)$ & 65.7 & 0.4 \\
Global quality of life & $61.4(4.1)$ & 84.4 & 0.1 \\
Symptoms & & & \\
Pain & 35.9 & 72.7 & 0.8 \\
Nausea and vomiting & 16.4 & 13.5 & 0.3 \\
Dyspnea & 12.5 & 19.8 & 0.3 \\
Insomnia & 36.4 & 31.5 & 0.8 \\
Appetite loss & 29.1 & 44.1 & 0.06 \\
Constipation & 26.0 & 16.2 & 0.1 \\
Diarrhea & 15.6 & 18.9 & 0.7 \\
Fatigue & 44.7 & 36.8 & 0.1 \\
Financial difficulties & 61.4 & 61.2 & 0.5 \\
\hline
\end{tabular}

${ }^{\mathrm{a}}$ : Higher scores indicate a better condition, ${ }^{\mathrm{n}}$ : Higher scores indicate a greater degree of symptom

either in their demographic and clinical status (Table 1) or in their baseline quality of life scores (Table 2).

Totally, 89 patients were studied. There were no significant differences between the two groups either in their demographic and clinical status (Table 1) or in their baseline quality of life scores (Table 2).

However, at 1 month, 3 and 5-month follow-up assessments significant differences were observed. In one month follow-up two groups were significantly different in social functioning $(\mathrm{p}<0.05)$ indicating a better condition in the treatment group.

At the 3-month follow-up, social functioning, role functioning, nausea and vomiting and appetite loss were better in the treatment group (all p-values $<0.05$ ). At the 5-month follow-up, physical functioning, social functioning, role functioning, global quality of life, nausea and vomiting and 
Am. J. Applied Sci., 5 (7): 872-875, 2008

Table 3: Comparison of quality of life scores between two groups at follow-ups

\begin{tabular}{|c|c|c|c|c|c|c|c|c|c|}
\hline \multirow[b]{3}{*}{ Functioning $^{\mathrm{a}}$} & \multicolumn{3}{|c|}{1 month follow-up } & \multicolumn{3}{|c|}{3 months follow-up } & \multicolumn{3}{|c|}{5 months follow-up } \\
\hline & $\begin{array}{l}\text { Naltrexone } \\
(\mathrm{n}=45)\end{array}$ & $\begin{array}{l}\text { Placebo } \\
(\mathrm{n}=44)\end{array}$ & & $\begin{array}{l}\text { Naltrexone } \\
(\mathrm{n}=44)\end{array}$ & $\begin{array}{l}\text { Placebo } \\
(\mathrm{n}=43)\end{array}$ & & $\begin{array}{l}\text { Naltrexone } \\
(\mathrm{n}=33)\end{array}$ & $\begin{array}{l}\text { Placebo } \\
(\mathrm{n}=38)\end{array}$ & \\
\hline & Mean (SD) & Mean (SD) & $\mathrm{p}$-value & Mean (SD) & Mean (SD) & $\mathrm{p}$-value & Mean (SD) & Mean (SD) & p-value \\
\hline Physical functioning & $78.7(3.7)$ & $73.6(4.3)$ & 0.58 & $72(4.5)$ & $68.2(3.9)$ & 0.08 & $80(2.6)$ & $65.7(4.6)$ & 0.008 \\
\hline Role functioning & $72.9(5)$ & $98.9(4.4)$ & 0.1 & $76(4.7)$ & $65.7(4.3)$ & 0.1 & $92.7(2.1)$ & $71.1(5)$ & 0.00 \\
\hline Emotional functioning & $77.8(2.9)$ & 73.4 (3.6) & 0.7 & $72.3(2.7)$ & $71.7(3.3)$ & 0.7 & $72.9(3.4)$ & $69.1(3.4)$ & 0.4 \\
\hline Cognitive functioning & $92.7(2.6)$ & $85.1(3.9)$ & 0.8 & $88.5(3.2)$ & $90.5(2.9)$ & 0.4 & $89.5(3)$ & $90(2.7)$ & 0.8 \\
\hline Social functioning & $80.2(3)$ & $65.7(4.2)$ & 0.00 & $78.1(3.1)$ & $62.6(4.5)$ & 0.002 & $88(2.7)$ & $72(4.2)$ & 0.005 \\
\hline $\begin{array}{l}\text { Global quality of life } \\
\text { Symptoms }^{n}\end{array}$ & $68.4(3.4)$ & $59.6(4)$ & 0.5 & $63.2(3.5)$ & $55.6(3.6)$ & 0.1 & $34.6(3.4)$ & $41.8(3.8)$ & 0.00 \\
\hline Pain & $28.6(5.4)$ & $34.2(4.5)$ & & $31.2(4.7)$ & $34.2(4.9)$ & 0.6 & $27.6(5.4)$ & $29.7(5)$ & 0.7 \\
\hline Nausea and vomiting & $11.9(3.9)$ & $5.4(1.8)$ & 0.6 & $8.8(2.4)$ & $3.6(1.3)$ & 0.009 & $1(0.7)$ & $31.5(2.6)$ & 0.00 \\
\hline Dyspnea & $11.4(3.5)$ & $9.9(2.8)$ & 0.5 & $12.5(3.8)$ & $6.3(2.8)$ & 0.7 & $9.3(3.4)$ & $5.4(2.7)$ & 0.2 \\
\hline Insomnia & $29.1(4.9)$ & $37.8(5)$ & 0.5 & $25(4.4)$ & $30.6(5)$ & 0.4 & $31.2(5.7)$ & $34.2(5.2)$ & 0.5 \\
\hline Appetite loss & $26(5.3)$ & $35.1(4.8)$ & 0.2 & $2(1.4)$ & $50.4(4.2)$ & 0.00 & $3.1(2.2)$ & $8.6(3.7$ & 0.00 \\
\hline Constipation & $20.8(4.6)$ & $16.2(4)$ & 0.1 & $19.7(4.6)$ & $16.2(4)$ & 0.9 & $10.4(3.7)$ & $16.2(4.5)$ & 0.3 \\
\hline Diarrhea & $9.3(4)$ & $12.6(4.1)$ & 0.5 & $6.2(3.4)$ & $6.3(3.3)$ & 0.07 & $1.4(1)$ & $2.7(2)$ & 0.3 \\
\hline Fatigue & $31.9(4.6)$ & $37.8(4)$ & 0.2 & $44.7(5.2)$ & $43.2(4.5)$ & 0.3 & $45.8(6)$ & $52.5(5.1)$ & 0.3 \\
\hline Financial difficulties & $53.1(5.7)$ & $64.8(5.8)$ & 0.1 & $68.7(4.4)$ & $56.7(5.1)$ & 0.3 & $60.4(5.2)$ & $52.2(4.5)$ & 0.2 \\
\hline
\end{tabular}

${ }^{a}$ : Higher scores indicate a better condition, ${ }^{n}$ : Higher scores indicate a greater degree of symptoms

appetite loss were significantly better in the nalterxone group. The results are shown in (Table 3).

This was a randomized trial and showed that natrexone is an effective drug in henmatolgic cancer patients and can improve quality of life in this group of patients. Studies also have shown that the drug has objective effects on blood endorphins or shrinking the tumors ${ }^{[1,6,7,12]}$.

There were six areas that were significantly better in the naltrexone group compared with the placebo group. These are briefly are discussed as follows.

At the three-month follow-up,role functioning was significantly better in the naltrexone group indicating less restriction in daily works than the placebo group. Similarly physical functioning was better in the naltrexone group after 5 months, so that the naltrexone group had fewer problems in short and long walks, doing heavy works, or daily activities and less rest restriction due to physical condition. In addition social functioning in the naltrexone group was better than the control group and patients in the intervention group were less interrupted in social and financial affairs due to physical conditions. Finally global quality of life score in the naltrexone group was significantly better at the 5-month follow-up.

Patients receiving Naltrexone showed a better appetite, thus anorexia was reported less frequently by this group compared with the control group. It is under discussion that this might be due to increased endorphin ${ }^{[13]}$.

The other symptoms that were better in the naltrexone group in both 3 and 5-month follow-ups, were nausea and vomiting. This also indicates that endorphin secretion was increased in this group. Pain did not show significant differences between the two groups although pain control was better for the naltrexone group. In different studies analgesic effect of LDN has been shown. For example a study showed that LDN is effective in neuropathic pains $^{[14]}$. In contrast, studies indicated that LDN had no therapeutic effect on pain control especially in hyper algesic responses ${ }^{[15,16]}$.

\section{CONCLUSION}

In spite of the study limitations (for example the small sample size), the findings suggest that low dose naltrexone is an effective drug for treating hematologic cancer patients. The drug can improve quality of life and thus prescribing LDN to patients with cancer could be recommended.

\section{ACKNOWLEDGMENTS}

This study was funded by Hamedan university of medical sciences, Iran. In addition we would like to appreciate all patients who participated in this interventional study.

\section{REFERENCES}

1. WWW.Low dose naltrexone.org

2. Good, P., 2006. low dose naltrexone for multiple sclerosis and autism, does its benefit reveal acommon cause?, Medical Hypotesis, 3: $671-672$. 
3. Agward, Y. and A. Lucille, 2005. Low dose naltrexone therapy in multiple sclerosis, Medical Hypotesis, 64 (4): 721-724.

4. Honar, H., K. Riazi, H. Homayon and H. Sadeghipour, 2004. Ultra low dose naltrexone potentiates the anti convulsant effect of low dose morphine on clonic seizures, Neuroscience, 3 (129): 733-742.

5. Revital, K., E. Timny and R. Grenshpon, 2003. Low dose naltrexone for the treatment of irritable bowel syndrome. The Am. J. Gastroenterol., 98 (9): s268.

6. Makman, M., 1994. Morphine receptors in immunocytes and neurons, Adv. Neuroimmunol., 4: 69-82.

7. Roys, Loh H., 1996. Effects of opioids on the immune system. Neurochem Res., 21: 1375-1386.

8. Manual, P., L. Marion and L. Jean-Marie, 1995. Low dose naltrexone effects on plasma chemisteies and clinical symptoms in autism: A double blind, placebo-controlled study, psychiatry Res., 58 (3):191-201.

9. Sabine, A.J., A. Arnold, 1996. Anxiety and pain: Attentional and endorphinergic influences, Pain, 66 (2-3): 145-150.

10. Paolo, M., G. Edward and F. James, 2004. chronic very low dose naltrexone administration attenuates opioid withdrawal expression, Biological Psychiatry, 56 (4): 261-268.
11. Ian, S.Z., J. Patricia and Maclaughlin, 1987. Endogenous opioid systems regulate cell proliferation in the developing rat brain. Brain Res., 412 (1): 68-72.

12. Arntz, A., M. Harald and P. Dejong, 1993. Opioid antagonist affects behavioral effects of exposure in vivo. J. Consul. Clin. Psychol., 61 (5): 865-870.

13. Roys, Loh H., 1996. Effects of opioids on the immune system. Neurochem Res., 21:1375-1386.

14. Vanderah, T. and L. Burns, 2004. Ultra low dose naltrexone plus morphine blocks thermal hyperalgesia and attenuates mechanical hypersensitivity in a neuropathic pain model, Pain, 5 (3): s59.

15. Rockville, Shekelle P., 2003. Best case series for the use of immune-agumentation therapy and naltrexone for the treatment of cancer, Summary Evidence Report, Evidence Report/Technology Assessment: AHRQ Publication. NO3-EO29 April

16. Cantilena, Jr., C. Wright and C. Miller, 2004. Effects of low dose naltrexone on analgesia produced by hydrocodone. Clinical Pharmacol. Therapeutics, 75 (2): 71. 